\title{
A dignidade do homem: reflexões a partir de I. Kant
}

\author{
[The man's dignity: reflections departing from I. Kant]
}

\author{
Georg Sans, SJ*
}

\begin{abstract}
Resumo
O presente artigo consiste numa reflexão filosófica sobre a dignidade humana. Seu ponto de partida é a conexão feita por Kant entre a autonomia do sujeito com a concepção de dignidade absoluta da pessoa. Defende-se que o conceito de dignidade da pessoa não consiste apenas no que se faz para proteger a própria vida e garantir os próprios direitos, mas essencialmente também no uso que cada um faz da própria capacidade de juízo e da própria liberdade de decisão. Conclui-se que, se a dignidade fosse apenas uma questão que se refere a proteção da vida física, o Concílio Vaticano II não teria podido fundar o seu direito à liberdade religiosa, reportando-se à dignidade da pessoa humana.
\end{abstract}

Palavras-chave: Dignidade Humana; Kant; Autonomia; Liberdade Religiosa.

\begin{abstract}
This article consists in a philosophical reflection concerning the human dignity. It departs from the connection made by Kant between the subject's autonomy and - with - the person absolute dignity conception. One defends, back up that the person's dignity concept does not only consist which one makes of in order to protect its own life and to guarantee its own rights, but essentially also in the use that everuone makes from its judgement own capacity and from its decision own liberty. One concludes that, if the mentioned dignity were only a matter that refers to the physical life protection - to the protection concerning the physical life - the Vatican Council II should not have been able to establishe to the religious liberty using, as a frame of references, the human person dignity.
\end{abstract}

Key-words: Human Dignity; Kant; Autonomy; Religious Liberty.

\section{Introdução}

A declaração do Concílio Vaticano II acerca da liberdade religiosa possui o significativo título de Dignitatis humanae. Consoante a concepção do Concílio, a dignidade da pessoa humana

\footnotetext{
*Professor für Religions- und Subjektphilosophie an der Hochschule für Philosophie/München, Alemanha, email; georg.sans@hfph.de. Título original LA DIGNITÀ DELL'UOMO Riflessioni alla luce del pensiero di I. Kant, in La Civiltà Cattolica 2015 I 440-450, 3953 (7 marzo 2015). Tradução: DaniloVazCurado R M. Costa (UNICAP/PE).
}

Ano $15 \cdot$ n. $1 \cdot$ jan./jun. $2015-31$ 
constitui o fundamento do direito à liberdade religiosa. Os Padres conciliares se ocuparam deste argumento com particular amplitude. Os debates acerca da liberdade religiosa se prologaram por todas as quatro sessões. No outono de 1965, o texto foi aprovado pela assembleia plenária dos Bispos com ampla maioria e foi promulgado pelo Papa Paulo VI. As reflexões que seguem, se colocam numa perspectiva filosófica, e reportam-se não tanto a liberdade religiosa, mas quanto ao que lhe está na base, isto é, a dignidade do homem "a qual tem feito conhecer a palavra de Deus revelada e a própria razão"1.

O ponto de partida dá-se a partir das afirmações iniciais do documento, que assume um caráter programático: "na época contemporânea os seres humanos tornam-se sempre mais conscientes da própria dignidade da pessoa e cresce o número daqueles que exigem agir por sua iniciativa, exercitando a liberdade própria, responsável, tomada da consciência do dever e não

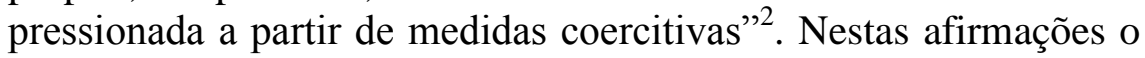
discurso acerca da dignidade da pessoa humana se refere portanto, em geral, à autodeterminação responsável e, mais em particular, ao livre exercício da religião. Outros exemplos de um agir responsável seria o desenvolvimento da atividade econômica ou a participação na vida política. Mas, ao mesmo tempo, com o direito à autodeterminação se alcança apenas um aspecto parcial disto que se devem compreender por dignidade do homem. Para que se possa exercitar corretamente o próprio direito à autodeterminação é preciso satisfazer outros requisitos. Se aos cidadãos de um determinado país falta o que é estritamente necessário - alimentos, vestimentas, habitação, cuidados médicos -, não se pode falar de vida digna.

Numa nota de rodapé, relativa à primeira parte da Declaração Dignitatis humanae, os padres conciliares citam a Encíclica Pacem in terris de João XXIII, que fora publicada anteriormente há dois anos e meio. Em plena guerra fria, o Papa convidava à paz e recordava a dignidade da pessoa que devia caracterizar toda ordem humana. Igualmente, ele se reportava ao fato de que vários direitos à liberdade, assim como a

\footnotetext{
${ }^{1}$ Concilio Vaticano II, Declaração Dignitatis humanae, n. 2.

${ }^{2}$ Idem.

32 • Universidade Católica de Pernambuco
} 
responsabilidade e os deveres da pessoa singular, como também da sociedade, tem como sua base o direito à existência e a um modo de vida digno. ${ }^{3}$ Quem não possui os meios necessários para manterse em vida já está lesado também no exercício dos seus demais direitos.

O conceito de dignidade da pessoa encerra por isto dois componentes. De um lado, esta dignidade exige que se protejam o corpo e a vida de todos. Neste sentido, este se manifesta no tratamento que cada um recebe dos demais, da sociedade e do Estado. De outro lado, o conceito de dignidade se põe em relação com a capacidade que cada um possui à autodeterminação. A dignidade da pessoa, portanto não consiste apenas nisto que os outros fazem para proteger a própria vida e garantir os próprios direitos, mas essencialmente também no uso que cada um faz da própria capacidade de juízo e da própria liberdade de decisão. Nesta perspectiva, representa sem dúvida um progresso o fato que aumenta o número daqueles que, conscientes da própria capacidade de autodeterminação, exigem que os seus direitos à liberdade sejam reconhecidos e não sejam delimitados por medidas coercitivas.

\section{De Cícero à Kant}

Para esclarecer posteriormente a relação que perpassa entre os dois componentes que havíamos mencionado - a livre autodeterminação e a responsabilidade face aos demais -, é preciso remontar a história do conceito de dignidade humana. Merece ser levada em consideração, sobretudo a filosofia de Immanuel Kant, que conectou expressamente a autonomia do sujeito com a concepção de dignidade absoluta da pessoa. Segundo este filósofo, a autonomia é "o fundamento da dignidade da natureza humana e de toda natureza racional"4. Deixemos de lado a questão de quais são os seres racionais, além do homem, aos quais se poderia aplicar o conceito kantiano de autonomia. Permanece claro, contudo que Kant não atribuí de modo algum a um animal a capacidade de autodeterminação, mas compreende a dignidade como um traço característico do homem.

\footnotetext{
${ }^{3}$ Cfr Giovanni XXIII, s., Enciclica Pacem in terris, n. 6.

${ }^{4}$ Kant, Fondazione della metafisica dei costumi, Roma, Laterza, 1997, p. 105.
} 
Com esta sua concepção da preeminência do homem, Kant se põe numa longa trilha de pensadores que se pode remontar à antiguidade. Já Cícero em seu tratado De officiis (Sobre os deveres) sublinhava a superioridade do homem nos confrontos com as feras e os demais animais. Enquanto estes últimos dirigem-se apenas por seus prazeres e se deixam guiar por seus instintos, o espírito do homem progride com a reflexão, e a razão põe um limite ao gozo dos sentidos. Tendo consciência da excelência e da dignidade da nossa natureza "compreendemos como vergonhoso chafurdar no luxo e viver com toda refinada suavidade e quanto é honesto, ao invés, uma vida frugal, moderada, contida, severa e sóbria". 5

$\mathrm{Na}$ tradição judaico-cristã sempre foi conectada a dignidade da pessoa à ideia que o homem é imagem de Deus, como se afirma na narrativa da criação. Criando o homem à sua imagem e semelhança $^{6}$, Deus o colocou numa posição particular em relação a todas as demais criaturas. Esta situação singular do homem não influi em nada sobre a sua fragilidade. A narrativa bíblica do pecado original é um testemunho eloquente. Diversamente dos demais animais, que se desenvolvem mais ou menos segundo ao que é intrínseco a sua natureza, o homem possui a possibilidade de ofuscar a imagem de Deus e de torcer a própria natureza.

A depender do ponto de vista, a liberdade do homem à autodeterminação pode ser considerada um privilégio único ou uma fraqueza. Enquanto próximo ao final da Idade Medieval se foi conferido importância a miséria humana, com o início do Renascimento se alterou o registro. $\mathrm{O}$ contributo mais famoso a esta temática é constituído pelo discurso de Giovanni Pico della Mirandola acerca da dignidade do homem, publicado em 1496 com o título de Oratio. Porém, antes dele devemos mencionar o tratado De dignitate et excellentia hominis (Sobre a dignidade e excelência do homem) de Giannozzo Manetti de 1452. Após ter descrito amplamente a perfeição do corpo e do espírito humano, este autor exalta a dignidade do homem integral, que na arte e na técnica imita a atividade criadora de Deus.

A respeito desta afirmação, a novidade do discurso de Pico della Mirandola consiste no fato de que a função do homem não

\footnotetext{
${ }^{5}$ Cicerone, Opere politiche e filosofiche, vol. I, Torino, Utet, 1974, p. 647.

${ }^{6} \mathrm{Cf}$. Gen $1,26$.

$34 \cdot$ Universidade Católica dePernambuco
} 
está fixada no início da criação. Num hipotético discurso de Deus a Adão, se diz "Não te criamos nem celeste, nem terreno, nem mortal ou imortal, de modo tal que tu, quase voluntário e honorário escultor e modelador de si próprio, possa forjarte do modo que preferires"7.

Nesta abertura face a própria determinação consiste a característica da humanidade. Ao homem não vem posto limites, mas ele mesmo deve desenvolver sua própria natureza. Ele é semelhante a um camaleão, que de um lado pode "degenerar nos seres inferiores, ou seja, nos animais brutos" e de outro, segundo a sua vontade, pode "ser regenerado nos seres superiores, ou seja, nas criaturas divinas" $"$. Como diz expressamente esta última frase, a ideia de arbítrio ou de capricho é de todo estranha a Pico. Para ele, obviamente, é auspicioso que nós não nos transformemos em bestas, mas nos elevemos face a Deus. Como via mais apropriada para alcançar este objetivo ele indica a filosofia.

Todavia, no discurso de Pico della Mirandola se procurará em vão a palavra dignidade. Não obstante o uso frequente do termo, sobretudo no Século V, será Immanuel Kant que definira o sentido preciso da palavra "isso que não tem preço, e, portanto não admite nenhum equivalente, possui uma dignidade" $"$. Com esta afirmação ele se refere claramente a oposição entre dignidade da pessoa e lógica do mercado. Contanto que algo tenha preço determinado, o seu valor é relativo. Pode ser trocado sempre com uma outra coisa que tenha um valor igual ou superior ao seu. Tudo o que possui um equivalente é em linha de princípio venal. O que está para além de todo preço se subtrai à lógica do mercado. Posto que possui um valor não relativo, mas absoluto, não é comerciável, nem negociável. Neste raciocínio reside a origem da ideia de dignidade do homem. Como se pode justificar tal concepção?

\section{O homem fim em si mesmo}

Para Kant, o conceito de dignidade absoluta do homem deriva da natureza vinculante da lei moral. O filósofo alemão, antes

\footnotetext{
${ }^{7}$ G. Pico della Mirandola, Discorso sulla dignità dell'uomo, Parma, 2003, p. 11.

${ }^{8}$ Idem.

${ }^{9}$ Kant, Fondazione della metafisica dei costumi, p. 103.
} 
de tudo não compreende a dignidade como um dado fático do qual se possa fazer derivar o dever moral de proteger a vida e de respeitar a dignidade da pessoa. No segundo capítulo da Fundamentação a metafísica dos costumes, ele procede, ao contrário, numa direção oposta. Se questiona, antes de tudo, quais são os princípios da moral e então conecta o conceito da dignidade do homem, compreendida como uma realidade que está sob a lei moral.

Se escreveu e discutiu-se muito acerca do fundamento da ética de Kant e acerca do assim designado imperativo categórico. Se, porém, for lido o texto de modo não tendencioso, não pode haver dúvida que o filósofo se preocupa, antes de tudo, em esclarecer em que consiste a consciência do dever moral, a voz da consciência, que nos induz com vigor irrefreável a fazer determinada coisa e a abandonar outras.

Kant estava convencido que um semelhante sentido do dever tinha uma justificação apenas se não dependesse de qualquer que fosse o fato causal. O saber se algo é moralmente bom ou mal não pode ser naturalmente uma questão que concerne a sociedade, a educação, as circunstâncias particulares, as crenças religiosas, as preferências pessoais ou aos genes, mas deve seguir normas absolutamente universais e necessárias que possam advir apenas da razão. Esta consideração conduziu Kant a acreditar que por trás de cada preceito moral, por trás de todos os juízos morais há um princípio único.

Posto que a lei prática não descreve simplesmente uma realidade de fato, mas é a norma suprema daquilo que devemos fazer, ele define este princípio um imperativo; visto que sua validade não depende de outros fatores e não está ligada a algum condicionamento restritivo, ele fala de um imperativo categórico. Kant se esforça em procurar qual é a fórmula justa com a qual exprime a lei fundamental da moral. A sua resposta em última análise não é de todo unitária, mas elenca diversos modos com o qual se pode compreender o imperativo categórico. A fórmula mais apta para isto que estamos falando soa assim "ages de modo a tratar a humanidade, assim na tua pessoa como na pessoa e todos os outros, sempre como fim, e nunca simplesmente como meio" ${ }^{\text {"10 }}$.

${ }^{10}$ Ibidem, p. 91.

36 • Universidade Católica de Pernambuco 
Para compreender o sentido do preceito, devemos compreender que coisa significa servir-se de um homem como meio ou como fim. Comecemos com o primeiro significado. Suponhamos que para o fim de semana eu projete ir de carro à praia, mas o meu carro esteja quebrado; a realização de meu propósito depende então essencialmente do fato de encontrar alguém que conserte meu carro. Se não estou em condições de fazê-lo eu mesmo e conduzo o carro a uma oficina, necessito do mecânico para realizar meu objetivo. Normalmente não há nada a contraditar disto, porque o mecânico foi pago pelo conserto realizado, pelo qual também é seu interesse ajudar-nos. Se proponho a quem quer que seja a possibilidade de fazer algo que ele faz por vontade própria ou que responde a suas intenções, utilizo-o em conjunto como um meio e como um fim. Como mostra o exemplo do mecânico, nisto não há nenhum problema, e antes esta deveria ser a situação normal. A nossa convivência social se funda sob o fato que nós nos ajudamos uns aos outros como meio para alcançar os fins uns dos outros. Os médicos curam os doentes, os professores educam as crianças, os construtores constroem casas e os agricultores produzem grãos, sem que nenhum deles considere ser explorado ou instrumentalizado. Em essência, considerar um homem tanto como meio quanto como fim é a situação menos relevante, que não põe dificuldade sob o plano moral.

Pode porém acontecer que se seja tratado de um modo tal que não se tenha sido levado em consideração os nossos desejos e projetos. Se alguém tem em mente apenas a realização dos próprios interesses, há necessidade de outrem simplesmente apena como meio e não em conjunto como fim. Exemplos significativos a este respeito são os trabalhos forçados e a escravidão, o abuso sexual, a tomada de reféns e a chantagem. Em todos estes casos a livre determinação da vítima não tem nenhum papel; a pessoa em questão, ao contrário, serve apenas como meio para atingir os intentos egoísticos dos malfeitores. Menos claro, mas análogo, é o caso da falta de respeito pelos outros. Quem, por exemplo, considera os funcionários públicos ou os empregados de uma empresa de limpeza como fornecedores de uma prestação, sem ter em conta o fato que são pessoas, se servem deles certamente não como um fim e agem, por isto, contra o imperativo kantiano.

"Servir-se de alguém como fim" significa portanto Ano $15 \cdot$ n. $1 \cdot$ jan./jun. $2015-37$ 
reconhecer a capacidade da pessoa de autodeterminar-se livremente e responsavelmente. De um ser que possui a capacidade de determinar os próprios fins, Kant diz que ele é fim em si mesmo. A pessoa do homem, afirma Kant na Metafísica dos Costumes, é deve ser apreciada como fim em si mesmo. "Em outros termos, ele possui uma dignidade (um valor interior absoluto), com o qual ele constrange todo os outros seres racionais a ter respeito por ele, e graças ao qual pode competir uns com os outros sob um plano de paridade".

\section{A Humanidade na pessoa de cada um}

$\mathrm{Na}$ fórmula do imperativo categórico a igualdade de todos se exprime com estas palavras: "a humanidade, assim na tua pessoa como na pessoa dos demais". Mas, porque Kant escolhe esta expressão tão complicada e não disse simplesmente "todo homem", ou "todas as pessoas"? Qual a diferença entre a humanidade e a pessoa de cada um? Enquanto desde a antiguidade tardia o conceito de pessoa indica o indivíduo na sua unicidade e em seu caráter insubstituível, o conceito de homem designa o gênero. Ao gênero humano pertence essencialmente a unidade de corpo e alma, ou de corpo e espírito. $\mathrm{O}$ homem não pode existir sem o seu organismo. Ao contrário, o que toca as pessoas, pode mesmo tratar-se simplesmente de realidades espirituais, como mostra o exemplo da Santíssima Trindade. Quando Kant fala da humanidade na pessoa de cada um, se refere claramente à oposição entre indivíduo e gênero e entre corpo e espírito.

Segundo o filósofo francês Paul Ricoeur, Kant usando a palavra humanidade, pretende dizer que não existe contradição entre a ideia de autonomia do sujeito e aquela de diversidade das pessoas. ${ }^{12}$ A lei moral estabelece uma conexão entre a vontade do indivíduo e a comunidade de todos, enquanto ordena considerar a humanidade na pessoa de cada um sempre em conjunto como um fim. Ricoeur recorda, não obstante que a sabedoria popular exprime uma exigência semelhante, quando na regra de ouro recomenda de

\footnotetext{
${ }^{11}$ Kant, Metafisica dei costumi, Milano, Bompiani, 2006, p. 485.

${ }^{12}$ Cf. P. Ricœur, Sé come un altro, Milano, Jaca Book, 1993, p. 324. 38 - Universidade Católica de Pernambuco
} 
"apenas fazer aos outros aquilo que agrada a si", uma determinada ação é moralmente boa ou má, geralmente é suficiente perguntar-se se gostaria ser tratado a mesma maneira Do mesmo modo que a regra de ouro, o imperativo categórico, tende a "estabelecer a reciprocidade lá onde reina a falta de reciprocidade" 14 .

Todavia se interpretaria errado o imperativo categórico, se o entendesse apenas no sentido que todos os homens devem tratar-se um ao outro da mesma maneira. A reciprocidade da qual fala Ricoeur refere-se não tanto as ações concretas mas ao reconhecimento da dignidade de cada pessoa. A igualdade da dignidade pode comportar por vezes num tratamento de todo diverso. Consideremos, por exemplo, o caso de uma pessoa que aparentemente sem culpa, cai numa situação de necessidade da qual não pode colocar-se fora com suas próprias forças. Suponhamos que eu veja alguém que cai num rio de uma ponte. E bem ao meu lado está posto um colete salva vidas, que apenas devo lançar para salvar aquele homem do afogamento. O dever de prestar ajuda a quem tem necessidade não deriva neste caso do fato que eu espere ser ajudado se um dia eu viesse a me encontrar numa situação crítica semelhante. Nem sequer pode ter uma função ou cálculo isto é, que o salvou, ou qualquer outro, poderia ser-me grato de todo modo pela minha boa ação. Ao contrário, sou obrigado a ajudar mesmo quando não se espera que a outra pessoa me seja útil no conseguir os meus próprios fins.

Aquele que sem segundos fins ou intenções ocultas salva alguém de afogar-se, de certo modo trata a pessoa simplesmente como fim e não como meio. Isto não obstante acontece, propriamente porque o outro, na situação concreta de necessidade na qual se encontra não está em condições de servir-se da própria capacidade de autodeterminação. Esta última seria de fato a condição pela qual poderei tratar o outro seja como meio, seja como fim. Posto que tal possibilidade vem menos, o servir-se de uma pessoa simplesmente como meio vai contra o imperativo categórico, este é o caso que representa no melhor modo o tratamento da pessoa como fim.

\footnotetext{
${ }^{13} \mathrm{~Tb} 4,15$.

${ }^{14}$ P. Ricœur, Sé come un altro, p. 326.
} 
Gerold Prauss numa aguda análise da fórmula kantiana, se reporta à parábola do Samaritano que se refere ao homem que no caminho entre Jerusalém à Jericó, cai nas mãos dos salteadores afirmando "Se é absolutamente necessário considerar o sujeito fim em si mesmo, o é do mesmo modo não mais possível considerar um sujeito também como meio e somente também como fim em si mesmo, mas quando é unicamente possível considerar um sujeito simplesmente como fim em si mesmo, como tal como aquele ferido, quase morto da parábola do bom samaritano na Bíblica"15. O comando do amor ao próximo de que nos fala Jesus no Evangelho, não faz distinção, mas auxilia aquele ferido na sua situação concreta de necessidade.

Se compreende assim como está fundado o discurso de Kant, quando fala da humanidade na pessoa de cada um. O motivo imediato pelo qual o Samaritano se volta aos necessitados é que se trata de um homem que necessidade de seu auxílio. Naquele momento o Samaritano não se pergunta se aquela vítima quer ser ajudado ou se, talvez, não merece a sua ajuda. $\mathrm{O}$ sentimento que o induz a assistir ao outro surge, por assim dizer, de modo espontâneo. É como se fosse suficiente considerar um indivíduo do gênero humano para ver nele um fim em si mesmo. Todavia, Kant não reconduz simplesmente o dever moral ao dado biológico segundo o qual a pessoa pertence ao gênero humano. Ele sublinha, ao contrário, que "somente a moralidade e a humanidade enquanto seja capaz desta constitui o que possui dignidade"16. O fundamento pelo qual as pessoas não possam nunca serem utilizadas como meios é a capacidade do homem de ser moral, a saber, de pôr a si mesmo seus fins e de assumir a responsabilidade das próprias ações.

Posto que o dever moral se refere à humanidade na pessoa de cada um, a partir do imperativo categórico kantiano não se pode deduzir que a dignidade do homem se possa restringir a um determinado grupo de pessoas. Em particular, seria errado negar a dignidade a todos aqueles que não são capazes de moralidade,

15 G. Prauss, Moral und Recht im Staat nach Kant und Hegel, Freiburg München, Alber, 2008, p. 70. Cf. Lc 10,29-37. Veja-se também G. Sans, „Gerold Prauss über Moral und Recht im Staat nach Kant und Hegel", In: Theologie und Philosophie 85, 2010, p. 185-202.

${ }^{16}$ Kant, Fondazione della metafisica dei costumi, p. 103.

40 - Universidade Católica dePernambuco 
porque, por exemplo, não estão em plena posse das suas faculdades físicas e espirituais. Uma semelhante delimitação da dignidade seria já contraditória pelo fato de que, como temos visto, o dever moral de ajudar se refere de modo próprio àqueles indivíduos que, encontrando-se numa situação de necessidade, estão impedidos de tudo ou em parte da sua capacidade de autodeterminar-se. Kant fala intencionalmente da capacidade da moralidade não da pessoa, mas da humanidade. Posto que a humanidade é capaz da moralidade, devo trata-la na pessoa de cada um nunca simplesmente como meio, mas sempre conjuntamente como fim.

A dignidade depende do pertencimento da pessoa a humanidade, de um lado, e da capacidade da moralidade por parte da humanidade, do outro. A dignidade do homem não se restringe quando a pessoa singular não possui discernimento moral suficiente, como no caso das pequenas crianças ou daqueles que são mentalmente impedidos. Mesmo quando o indivíduo não é consciente do seu dever e não reconhece o que é o bem, seu pertencimento à humanidade e a capacidade de moralidade por parte da humanidade garantem a dignidade de tal pessoa. Com a expressão "a humanidade assim na tua pessoa como na pessoa de todo o outro", que a primeira vista parece um tanto quanto obscura, Kant põe sob o mesmo pano a universalidade da dignidade humana - que se aplica a cada membro singular do gênero humano - e o seu fundamento na natureza espiritual do homem - a dignidade se funda sob a consciência do dever e sob a capacidade de por a si mesmo nos fins.

Se se elimina esta tensão e se põe como absoluto somente um dos dois fatores, se reduz a natureza particular da dignidade humana. De um lado, se tem observado apenas a partir da natureza racional da pessoa e se nega a dignidade a todos os indivíduos que, pela condição da idade, da doença e de qualquer outro motivo, não estão na plena posse da razão; e então, por exemplo, a pessoa idosa ou deficiente poderia, por arbítrio, ser utilizada simplesmente como meio, ou ser posto a parte, porque já não serve mais a nada. De outro lado, se reporta-se a dignidade ao simples pertencimento biológico do gênero e se deixa perder a capacidade do homem de autodeterminar-se; e, então, a vida humana conserva certamente aquele seu valor que a põe acima de qualquer outra coisa, mas a atenção que se confere a vida não tem mais nada a ver com a 
capacidade da moralidade e com o livre desenvolvimento da pessoa.

Se a dignidade fosse apenas uma questão que se refere a proteção da vida física, o Concílio Vaticano II não teria podido fundar o seu direito à liberdade religiosa se reportando a dignidade da pessoa humana. Para o Concílio, a dignidade é conferida a cada indivíduo e todos possuem a liberdade de gerir de modo responsável as próprias opiniões e as próprias ações. 